\section{Commentary: The challenge of postoperative diaphragmatic paralysis in patients with functionally univentricular circulation: A data-driven strategy}

\author{
Jeffrey P. Jacobs, MD, ${ }^{a}$ Charles D. Fraser III, MD,
} James S. Tweddell, MD, ${ }^{\mathrm{d}}$ and

Marshall L. Jacobs, MD

Kumar and colleagues ${ }^{1}$ are to be congratulated for their thoughtful analysis of 30 patients who underwent diaphragm plication for evidence of diaphragmatic paralysis as a complication of a surgical procedure at some point in time before Fontan completion. These 30 patients represent $2.6 \%$ of 1146 patients who underwent surgical management of functionally univentricular physiology at their institution during the period 1997 to 2015. Each of these 30 patients was compared with 2 propensity-matched control patients without evidence of diaphragmatic paralysis drawn from the universe of patients at their institution who underwent superior cavopulmonary anastomosis(es) (ie, Glenn) or Fontan procedure during the same timeperiod. Of the 30 patients who had undergone diaphragm plication, 24 patients subsequently underwent completion of the Fontan circulation, 5 are awaiting Fontan completion, and 1 died.

The authors report the following results: (1) There was no difference in pulmonary arterial pressure or pulmonary vascular resistance (PVR) between the plicated patients and their propensity matched controls at pre-Glenn catheterization and at pre-Fontan catheterization. (2) Both groups had comparable chest tube output and hospital length of

\footnotetext{
From the a Division of Thoracic and Cardiovascular Surgery, Department of Surgery, Congenital Heart Center, University of Florida, Gainesville, Fla; ${ }^{\mathrm{b}}$ Department of Surgery, University of Pennsylvania, Philadelphia, Pa; ' Department of Surgery, Johns Hopkins University School of Medicine, Baltimore, Md; and ${ }^{\mathrm{d}}$ Department of Cardiothoracic Surgery, Heart Institute, Cincinnati Children's Hospital Medical Center, Cincinnati, Ohio.

Disclosures: The authors reported no conflicts of interest.

The Journal policy requires editors and reviewers to disclose conflicts of interest and to decline handling or reviewing manuscripts for which they may have a conflict of interest. The editors and reviewers of this article have no conflicts of interest.

Received for publication July 2, 2020; revisions received July 2, 2020; accepted for publication July 2, 2020; available ahead of print July 19, 2020.

Address for reprints: Jeffrey P. Jacobs, MD, Department of Surgery, University of

Florida, Gainesville, FL 33701 (E-mail: JeffJacobs@msn.com).

J Thorac Cardiovasc Surg 2020;160:1297-9

$0022-5223 / \$ 36.00$

Copyright (C) 2020 by The American Association for Thoracic Surgery

https://doi.org/10.1016/j.jtcvs.2020.07.003
}

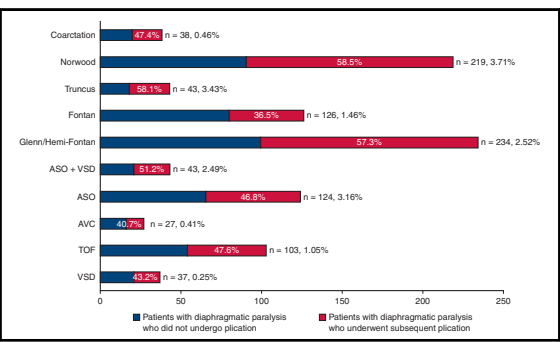

This analysis of The STS Congenital Heart Surgery Database reveals substantial variation in the use of diaphragm plication in patients with postoperative diaphragmatic paralysis: Blue indicates patients with diaphragmatic paralysis who did not undergo plication and red indicates patients with diaphragmatic paralysis who underwent subsequent plication.

\section{CENTRAL MESSAGE \\ A recent analysis of the STS Congenital Heart Surgery Data- base documented that substan- tial variability exists regarding the use of diaphragm plication in patients with postoperative dia- phragmatic paralysis. Kumar and colleagues provide important data to help guide the manage- ment of these challenging patients.}

stay at the time of Fontan completion. (3) Equal proportions of patients in both groups received pulmonary vasodilator therapy and/or supplemental oxygen at hospital discharge following Glenn operation and also following Fontan completion. The authors conclude: "Prior diaphragm plication does not adversely impact Fontan completion in children with single ventricle physiology. The hospital course during subsequent stages of palliation for plicated patients is no different than that of matched controls."

Importantly, the authors comment that no prospective studies exist to help guide the management of postoperative diaphragmatic paralysis in functionally univentricular patients. Because the total cavopulmonary connection is a passive low-pressure system that is sensitive to PVR, anything that increases PVR, such as elevated diaphragm causing decreased lung volume, can adversely impact short-term and long-term physiology. Apart from the influence of diminished lung volume, the paradoxical movement of a paralyzed hemidiaphragm during inspiration may negate 
the favorable influence that normal spontaneous breathing (as opposed to mechanically supported positive pressure ventilation) has on transpulmonary flow and thus overall cardiac output. Therefore, the authors plicate both all elevated and all paradoxically moving diaphragms in all patients with functionally univentricular physiology. Their protocol is that following surgery, if a patient is unable to wean from mechanical ventilatory support as expected, or if a hemidiaphragm is elevated on chest radiography, then fluoroscopic evaluation during spontaneous breathing is performed to assess diaphragmatic movement. In patients with functionally univentricular hearts, if a hemidiaphragm is found to move paradoxically, or is immobile in an elevated position, then hemidiaphragm plication is performed. Meanwhile, for patients with biventricular physiology, if a hemidiaphragm is found to move paradoxically, or is immobile in an elevated position, then plication is only performed in patients who fail extubation.

This analysis, and the advocacy of the authors for a specific approach to patients with diaphragmatic paralysis, provide data-driven guidance for the management of these challenging patients. The magnitude of this challenge on a national level can be appreciated from a recent analysis of The Society of Thoracic Surgeons Congenital Heart Surgery Database (STS-CHSD). ${ }^{2}$ The STS-CHSD was queried to identify children who experienced diaphragmatic paralysis after cardiac surgery (2010-2018; 126 centers). Results showed that 2214 of 191,463 patients ( $1.2 \%$ of patients undergoing pediatric cardiac surgery) experienced diaphragmatic paralysis. Postoperative diaphragmatic paralysis portended worse outcomes, including mortality $(5.6 \%$ vs $3.5 \% ; P<.001)$, major morbidity $(37.2 \%$ vs $10.7 \% ; P<$ $.001)$, tracheostomy $(7.1 \%$ vs $0.9 \% ; P<.001)$, prolonged mechanical ventilation $(38.0 \%$ vs $7.8 \% ; P<.001)$, and 30 day readmission $(22.0 \%$ vs $10.6 \% ; P<.001)$. A total of 1105 of 2214 patients $(49.9 \%)$ with diaphragmatic paralysis underwent plication. Plication rates varied widely across centers. Patients who underwent plication were younger, smaller, had more risk factors, and had undergone more complex surgeries. There was no correlation between center volume and center risk adjusted rates of diaphragmatic paralysis $(R=0.05, P=.5)$ nor frequency of plication $(R=0.08, P=.4)$. Among the STS-CHSD benchmark procedure groups (Figure 1), the incidence of diaphragm paralysis was highest following Norwood procedure $(3.71 \%)$, truncus repair $(3.43 \%)$, arterial switch operation $(3.16 \%)$, and Glenn/hemi-Fontan $(2.52 \%)$. A total of $2.52 \%$ of all patients undergoing Glenn/hemi-Fontan ( $=234$ ) had postoperative diaphragm paralysis, with $57.3 \%$ undergoing plication, whereas $1.46 \%$ of all patients undergong the Fontan operation $(n=126)$ had postoperative diaphragm paralysis, with $36.5 \%$ undergoing plication. These data indicate that substantial center-level variability exists in the United States regarding

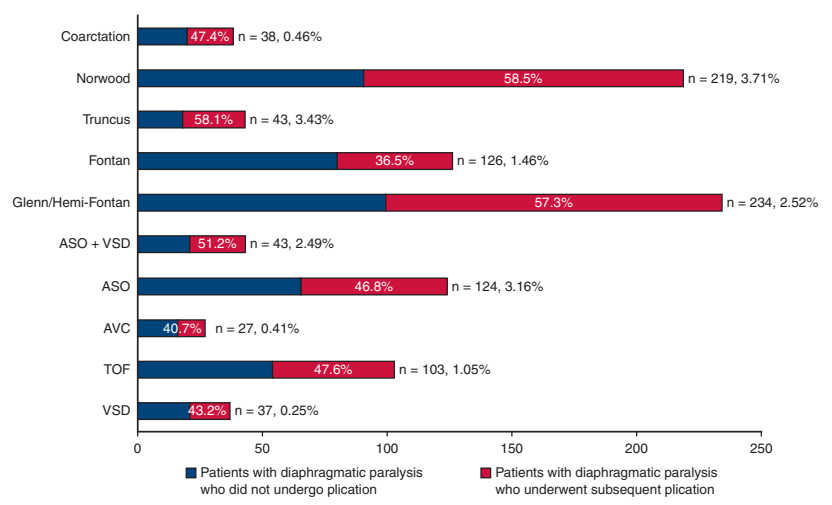

FIGURE 1. The Society of Thoracic Surgeons Congenital Heart Surgery Database was queried to identify children who experienced diaphragmatic paralysis after cardiac surgery (2010 to 2018; 126 centers); 2214 of $191,463(1.2 \%)$ patients undergoing pediatric cardiac surgery experienced diaphragmatic paralysis. ${ }^{2}$ This graph documents the overall incidence of diaphragm paralysis stratified by procedure group, further subdivided based on those who underwent plication (red) and those who did not (blue).

the use of diaphragm plication to treat postoperative diaphragmatic paralysis in patients with and without functionally univentricular hearts.

Kumar and colleagues ${ }^{1}$ are to be congratulated for providing important data to help guide the management of these challenging patients with functionally univentricular hearts and diaphragmatic paralysis. Their study strongly suggests that timely plication of a paralyzed hemidiaphragm in patients destined for eventual completion of the Fontan circulation can mitigate morbidities previously shown to complicate the short-term perioperative outcomes of Fontan completion operations. These observations provide rational support for a proactive approach to the management of diaphragm paralysis that occurs at the time of first-stage palliative procedures or at the time of superior cavopulmonary anastomosis(es). The same rationale would presumably apply to diaphragm paralysis occurring at the time of Fontan completion. With respect to long-term outcomes; however, a cautionary note should be considered. Hsia and colleagues ${ }^{3}$ used Doppler ultrasound to evaluate flows in the hepatic vein, portal vein, and subhepatic inferior vena cava, and showed that in patients with a paralyzed diaphragm, plication does not completely restore normal subdiaphragmatic venous hemodynamics. They showed that in Fontan patients with a plicated diaphragm, inspiration-derived hepatic venous flow is suppressed and portal venous flow loses its normal expiratory augmentation. These suboptimal features of splanchnic circulation in Fontan patients who have experienced diaphragm paralysis and undergone plication are similar to those noted in some patients with failing Fontan circulation. Long-term follow-up of patients such as those in the study by Kumar and colleagues ${ }^{1}$ will be necessary to see whether Fontan patients who had undergone prior 
plication of a paralyzed hemidiaphragm are at a higherthan-usual risk for protein-losing enteropathy or other modes of eventual Fontan failure, despite having enjoyed an uncomplicated early postoperative recovery. Notwithstanding the potential for recovery of function of a paralyzed hemidiaphragm, as well as the important observations of Kumar and colleagues ${ }^{1}$ regarding the potential benefit of prior plication in terms of mitigation of shortterm post-Fontan morbidities, it is a fact that the best strategy regarding phrenic nerve injury and diaphragm paralysis is to avoid it completely.
See Article page 1291.

\section{Commentary: Brains over brawn: Do strong diaphragm muscles matter?}

\author{
Lauren Kane, MD
}

Subramanyan and colleagues ${ }^{1}$ take an important look at the effects of diaphragmatic plication for diaphragm paresis and paralysis on successful completion of staged palliation in a population of patients with single-ventricle anatomy. Phrenic nerve injury during the course of congenital heart surgery, especially in children younger than age 2 years, is a significant source of morbidity. Most of the time, the phrenic nerve stays out of harm's way with meticulous technique and conscious avoidance of nerves. Various centers have reported anywhere from $2.2 \%$ to $4.8 \%$ occurrence of diaphragm paresis/paralysis. ${ }^{2,3}$ The loss of function of a hemidiaphragm can reveal itself as respiratory compromise, such as failure to wean from ventilator or nonsustainable increased work of breathing, especially in neonates and

\footnotetext{
From the Department of Surgery, University of Central Florida, Orlando, Fla. Disclosures: The author reported no conflicts of interest.

The Journal policy requires editors and reviewers to disclose conflicts of interest and to decline handling or reviewing manuscripts for which they may have a conflict of interest. The editors and reviewers of this article have no conflicts of interest.

Received for publication July 3, 2020; revisions received July 3, 2020; accepted for publication July 6, 2020; available ahead of print July 12, 2020.

Address for reprints: Lauren Kane, MD, Department of Surgery, University of Central Florida Medical School, 6850 Lake Nona Blvd, Orlando, FL 32827 (E-mail: Lckane@mac.com).

J Thorac Cardiovasc Surg 2020;160:1299-300

$0022-5223 / \$ 36.00$

Copyright (C) 2020 by The American Association for Thoracic Surgery

https://doi.org/10.1016/j.jtcvs.2020.07.011
}

\section{References}

1. Kumar SR, Bainiwal J, Cleveland JD, Pike N, Wells WJ, Starnes VA. Impact of prior diaphragm plication on subsequent stages of single ventricle palliation. $J$ Thorac Cardiovasc Surg. 2020;160:1291-6.e1.

2. Fraser CD III, Ravekes W, Thibault D, Scully B, Chiswell K, Giuliano K, et al Diaphragm paralysis after pediatric cardiac surgery: An STS Congenital Heart Surgery Database study. Ann Thorac Surg. August 4, 2020 [Epub ahead of print].

3. Hsia TY, Khambadkone S, Bradley SM, de Leval MR. Subdiaphragmatic venous hemodynamics in patients with biventricular and Fontan circulation after diaphragm plication. J Thorac Cardiovasc Surg. 2007;134:1397-405.

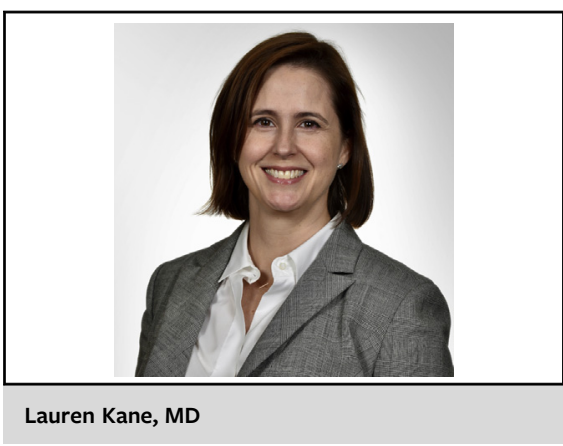

CENTRAL MESSAGE

Diaphragm plication for diaphragm paresis does not adversely affect pulmonary hemodynamics or progression through staged palliation for single-ventricle patients. infants. ${ }^{4}$ Various published studies examine the need for and timing of diaphragm plication in treatment of a paretic diaphragm. There is relative agreement on early 